\title{
MODERN APPROACH TO THE CHOICE OF COMPOSITIONS FOR TEMPORARILY BLOCK THE PRODUCTIVE RESERVOIR WELLS IN THE FIELDS WITH COMPLICATED MINING AND GEOLOGICAL CONDITIONS
}

• . сумов, . . гин , . . остюков

R. A. Gasumov, T. Sh. Vagina, S. V. Kostukov

ткрытое кционерное общество «еверо- вк зский н учно-исследов тельский проектный институт природных г зов» ( «ев в $\quad$ в з»), г.

лючевые слов : к пит льный ремонт скв жин; глушение скв жины; горно-геологические условия; конденсируем я тверд я фз; продуктивный пл ст; ном льно низкое пл стовое д вление

Key words: workover; well killing; mining and geological conditions; condensable solid phase; productive formation; abnormally low reservoir pressure

дним из условий поддерж ния высоких темпов добычи углеводородного сырья в нефтег зовой отр сли н современном эт пе является повышение к честв ремонтных p бот. жнейшей из технологических опер ций, ок зыв ющих существенное влияние н производительность скв жин в послеремонтный период, является глушение скв жин. лушение скв жин предусм трив ет комплекс мероприятий по подбору рецептуры, приготовлению и з к чке в скв жину специ льных жидкостей, обеспечив ющих безоп сное и без в рийное проведение ремонтных р бот.

роведение этих мероприятий с учетом условий конкретного месторождения является сложной $з$ д чей, т к к к жидкости глушения должны обеспечив ть эффектив-

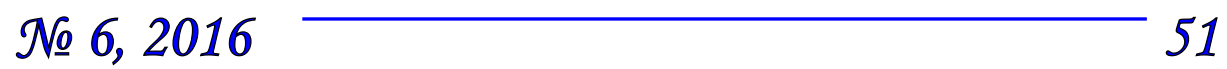


ность двух противоположных процессов - созд ние прочного непрониц емого 6 рьеp в пл сте и сохр нение фильтр ционно-емкостных свойств ( ) пл ст после проведения ремонтных р бот.

3 ключительной ст дии $\mathrm{p}$ зр ботки месторождений н иболее эффективным является способ глушения скв жин с временным блокиров нием продуктивного пл ст , сущность которого 3 ключ ется в 3 полнении скв жины в интерв ле продуктивного пл ст блокирующей жидкостью с целью созд ния изолирующего экр н . ри этом необходимое противод вление н пл ст созд ется технологической жидкостью, котор я р спол г ется в стволе скв жины н д блокирующей жидкостью.

лияние жидкостей глушения н продуктивность скв жин в послеремонтный период обусловлено, особенностями физико-химических процессов, протек ющих при вз имодействии блокирующего сост в с минер л ми продуктивного пл ст и с пл стовыми флюид ми. еличин этого воздействия существенно з висит от того, н сколько физико-химические и технологические свойств блокирующей жидкости соответствуют условиям ее применения. первую очередь следует учитыв ть п р метры пл ст коллектор (минер логический сост в, пл стовое д вление, пористость, прониц емость и др.) и физико-химические свойств флюидов, н сыщ ющих продуктивный горизонт.

ыбор компонентов блокирующего сост в должен осуществляться с учетом их миним льного нег тивного влияния н производительность скв жин.

ля предотвр щения кольм т ции пород коллектор, обусловленной глубоким проникновением в пл ст твердой ф зы блокирующего сост в, выбор кольм т нт должен осуществляться с учетом пористости и прониц емости пород-коллекторов.

редотвр щение обр зов ния в к н л х и пор х стойких эмульсий или нер створимых ос дков при вз имодействии пл стовых флюидов и фильтр т технологической жидкости достиг ется пр вильным выбором основы блокирующей жидкости (в г зовых скв жин х предпочтительными являются жидкости н водной основе, в нефтяных - н углеводородной).

охр нение продуктивного пл ст, ухудшение которых может быть обусловлено н бух нием глин, содерж щихся в к честве цементировочного м тери л в терригенных коллектор х, т кже уменьшение продуктивности скв жин з счет обр зов ния н поверхности пор дсорбционных гидр тных слоев, уменьш ющих эффективный p диус к н лов пор, может быть достигнуто использов нием химических доб вок солей, полимеров, поверхностно- ктивных веществ и др.

ыбор н полнителя является одной из в жнейших з д ч стоящих при р зр ботке и применении блокирующих сост вов [1]. ссортимент промышленно-выпуск емых н полнителей для нефтег зовой отр сли дост точно велик. о структуре их кл ссифицируют к к волокнистые, пл стинч тые (хлопьевидные) и зернистые (гр нулиров н-

ные). о своей природе н полнители подр зделяют следующим обр зом:

- минер льные ( сбест, слюд , к рбон ты к льция, м гния, желез );

- орг нические (торф, опилки, шелух орехов и др.);

- синтетические (целлоф н, отходы химических волокон, резинов я крошк и т. д.). дн ко не все эти н полнители могут успешно применяться в блокирующих сост в х ввиду высоких требов ний к их технологическим свойств м. иболее предпочтительными для применения в блокирующих сост в х являются кислотор створимые кольм т нты. то обусловлено тем, что в случ е недост точно к чественного уд ления блокирующего сост в в процессе освоения скв жины при созд нии депрессии н пл ст, восст новление коллекторских свойств может быть обеспечено кислотной обр боткой приз бойной зоны скв жины. связи с этим требов нием, перечень кольм т нтов для использов ния в блокирующих сост в х зн чительно суж ется.

p вильный выбор фр кционного сост в и использов ние к чественного з купорив ющего м тери л является з логом предотвр щения проникновения жидкой ф зы 
блокирующих и технологических жидкостей в пл ст и м ксим льного сохр нения коллекторских свойств. лишком мелкие ч стицы кольм т нт способны проник ть в поры коллектор н зн чительную глубину, что приводит к существенному снижению прониц емости коллектор и з труднению ввод скв жины в эксплу т цию после проведения ремонтных р бот. н оборот, слишком крупные ч стицы з купорив ющего м тери л не способны обр зовыв ть плотный блокирующий экр н в поровом простр нстве пл ст , что способствует высокой фильтр ции жидкой ф зы блокирующей жидкости в пл ст. ля определения оптим льного фр кционного сост в 3 купорив ющего м тери л в нефтег зовой отр сли применяют пр вило бр мс, согл сно которому средний (меди льный) р змер ч стиц кольм т нт должен р вняться или быть немного больше $1 / 3$ среднего р змер пор пл ст [2]. н лиз опыт применения p зличных н полнителей пок з л, что при использов нии кольм т нт с р змер ми ч стиц в ди п зоне 1/3-1/7 среднего ди метр пор происходит н иболее к чественное блокиров ние и м ксим льное сохр нение пл ст после освоения скв жин [3]. то объясняется тем, что крупные ч стицы из ук з нного ди п зон неглубоко проник ют в пл ст и созд ют своеобр зный к рк с. олее мелкие ч стицы 3 полняют промежутки между ч стиц ми в пор х пл ст . од действием гидрост тического д вления ч стицы уплотняются и созд ют прочный непрониц емый $б$ рьер, предотвр щ ющий поступление жидкой ф зы технологических жидкостей в пл ст.

дним из перспективных н пр влений, позволяющих зн чительно повысить эффективность ремонтных р бот, является использов ние при глушении скв жин сост вов с конденсируемой твердой ф зой, обр зующейся в результ те химических превр щений в процессе приготовления сост в и являющейся блокирующим гентом.

достоинств м т ких сост вов следует отнести следующее:

- конденсируем я тверд я ф 3 имеет конкретный 3 д нный химический сост в с миним льным содерж нием неконтролируемых примесей (в отличие от кольм т нтов природного происхождения);

- $\quad$ кр кционный сост в ч стиц кольм тирующего гент (конденсируемой твердой ф зы) может изменяться в дост точно широких предел х 3 счет корректировки содерж ния химических ре гентов в рецептуре блокирующего сост в ;

- кольм т нт обр зуется в блокирующем сост ве в результ те химического вз имодействия компонентов, что обеспечив ет повышение технологичности процесс приготовления и высокую однородность р спределения твердой ф зы в сост ве.

о химической природе т кие сост вы условно можно подр зделить н гидрогели, солегели и гидросолегели (смеш нн я форм конденсируемых дисперсий). первой группе относятся сост вы с конденсируемой твердой ф зой предст вленной гидроксид ми мет ллов. к пр вило, это гидрогели люминия или м гния. бр зов ние твердой ф зы в них происходит з счет химического вз имодействия водор створимой соли мет лл и щелочи. о второй группе относятся сост вы, в которых роль конденсируемой твердой ф зы выполняют нер створимые в воде соли мет ллов, н пример ч стицы силик т к льция.

едост тком и тех и других является дост точно узкий фр кционный сост в ч стиц. к, для гидрогелей х р ктерны морфные ч стицы м лого р змер , для солегелей - крупные крист ллические ч стицы. связи с этим т кие сост вы могут обеспечить эффективное блокиров ние только пл стов с однородной прониц емостью, что н пр ктике встреч ется дост точно редко.

того недост тк лишены гидросолегели. ни предст вляют собой сложные химические системы, в которых в к честве твердой ф зы выступ ют ч стицы гидроксидов и солей мет ллов р зличной формы и р змеров. бр зов ние дисперсной ф зы в т ких систем х происходит з счет одновременного протек ния ряд физико-химических процессов. ким обр зом, тверд я ф з в гидросилегелевых сост в х является поли-

№ 6,2016 53 
дисперсной со зн чительным р збросом ч стиц по р змер м. то позволяет успешно использов ть их для блокиров ния неоднородных по р змер м поровых к н лов продуктивных пл стов.

е менее в жным свойством блокирующего сост в является ингибиров ние н бух ния глинистых минер лов. од вляющ я ч сть нефтяных и г зовых месторождений приурочен к коллектор м трех типов: гр нулярным (обломочный, хемогенный), трещинным и смеш нного строения. р нулярные (терригенные) коллекторы сложены преимущественно песч но- левритовыми пород ми, состоящими из песч ников, песк , левролитов, реже - известняков, доломитов, мергелей. ементировочным м тери лом в т ких пород х, к к пр вило, являются глинистые минер лы, реже - к рбон ты. роме того глинистые минер лы встреч ются в коллектор х в виде прожилок и пропл стков.

лины продуктивных коллекторов состоят в основном из смеси глинистых минер лов: к олинитовых, монтмориллонитовых, гидрослюдистых, хлоритовых и других. х содерж ние в продуктивном пл сте может сост влять от долей процент до $30 \%$ и более.

ороды, включ ющие глинистые минер лы склонны к н бух нию, что х р ктеризуется увеличением объем обр зц породы и его вл жности. ким обр зом, процесс н бух ния глин приводит к снижению пористости и прониц емости породы. нтенсивность этого процесс существенно з висит от химического сост в жидкости в поровом простр нстве, концентр ции солей в ней, сост в обменных ионов, минер логического, гр нулометрического сост в пород, структуры породы, х р ктер ее внутренних связей. то обусловлено тем, что связи между гетерогенными слоями у глинистых минер лов могут быть р зличными в з висимости от особенностей строения слоя и его з ряд . некоторых глинистых минер лов они дост точно прочны и обеспечив ются вз имодействием томов кислород и гидроксильных групп (водородн я связь) или к тион ми, р спол г ющимися в межслоевом простр нстве (ионноэлектрост тическ я связь). других минер лов связь между слоями менее прочн я и обусловлен молекулярными сил ми [4].

ким обр зом, созд ние блокирующих сост вов, обл д ющих высокими блокирующими свойств ми и обеспечив ющих сохр нение пл стов, в том числе бл год ря ингибиров нию н бух ния глинистых минер лов пл ст -коллектор , является дост точно сложной з д чей, от решения которой существенно з висит продуктивность скв жины в послеремонтный период.

« ев в г з» имеет большой опыт $\mathrm{p}$ зр ботки технологических жидкостей и технологий глушения скв жин для месторождений с р зличными горногеологическими и клим тическими условиями [5-8]. дн ко, несмотря н высокую эффективность $\mathrm{p}$ зр бот нных р нее блокирующих сост вов н сегодняшний день в связи с возросшими требов ниями к п р метр м сост в вопрос усовершенствов ния и p зр ботки новых сост вов ост ется по-прежнему кту льным.

« ев в г з» был $\mathrm{p}$ зр бот н блокирующий сост в с конденсируемой твердой ф зой, выбр нной из числ кислотор створимых химических соединений. н обл д ет высокими блокирующими свойств ми (выдержив ет переп д д влений до 20 ) в терригенных коллектор х с неоднородной прониц емостью, содерж щих глинистые минер лы р зличного минер логического и химического сост в . роме того, блокирующий сост в обеспечив ет сохр нение пл ст (коэффициент восст новления прониц емости сост вляет более $95 \%$ ), т кже ингибиров ние н бух ния глинистых минер лов.

ри $\mathrm{p}$ зр ботке сост в были проведены исследов ния по изучению его влияния н н бух ние горных пород по методике . . иг ч и . . ров , учитыв ющей н ч льную пористость обр зц и объем иммобилизов нной жидкости. о д нной методике существующие методы оценки х р ктер вз имодействия $p$ зр б тыв емых со-

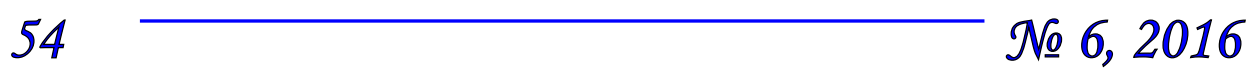


ст вов с глинистой породой б зируются н исследов нии процесс гидр т ции по коэффициент м н бух ния, р змок ния и скорости увл жнения.

сследов ния проводились н н тур льных керн х еверо- т вропольского месторождения, предст вленных мелоподобным мергелем и ргиллитом.

о результ т м исследов ний влияния р зр бот нного блокирующего сост в н н бух емость р зличных глинистых минер лов построены з висимости, предст вленные н рисунке.

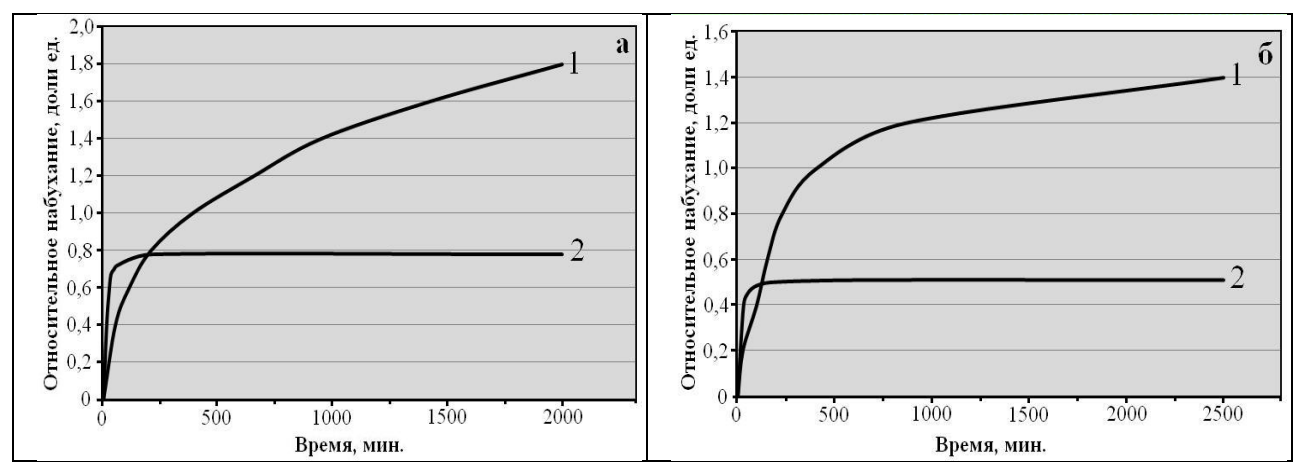

исунок. лияние блокирующего сост в с конденсируемой твердой ф зой

н н бух емостьмелоподобного мергеля ( ) и ргиллит (б):

1 -дистиллиров нн явод, 2 -р зр бот нный сост в

результ те исследов ний выявлено, что р зр бот нный сост в обл д ет высоким ингибирующим эффектом. это объясняется тем, что он содержит дв вид ингибирующих ч стиц к тионы и нионы, которые имеют р зличную природу и эффективны в глинистых минер л х, имеющих р зличную структуру и свойств , причем ингибирующие компоненты не вводятся дополнительно, обр зуются в процессе приготовления сост в в к честве побочных продуктов при формиров нии дисперсной ф зы, являющейся блокирующим гентом.

ким обр зом, проведенные исследов ния н глядно док зыв ют перспективность применения технологических жидкостей с конденсируемой твердой ф зой при глушении скв жин со сложными горно-геологическими условиями, в том числе в коллектоp х со зн чительным содерж нием глинистых минер лов. дн ко выбор рецептуры блокирующих сост вов должен определяться в строгом соответствии с конкретными условиями их применения.

писок литер туры

1. рылов . ., рецул . ., еденцев . . овременные технологические жидкости для з к нчив ния и к пит льного ремонт скв жин. сть $1 / /$ троительство нефтяных и г зовых скв жин н суше и н море. - 2015. № 1. - . .36-44.

2. Abrams A. Mud design to minimize rock impairment due to particle invasion // Journal of Petroleum Technology. 1977. - V. 29. - I. 5. - P. $586-592$.

3. Dick M. A., Heinz T. J., Svoboda C. F., Aston M. Optimizing the selection of bridging particles for reservoir grilling fluids. SPE International symposium on formation damage. - Lafayette, 2000. - . 58793.

4. околов . . линистые породы и их свойств // оросовский обр зов тельный журн л. - 2000. - . . 6. № 9. - . .59-65.

5. сумов . ., врилов . ., гин . . идросолегелевый блокирующий сост в и технология его применения н скв жин х п дно- ибирского нефтег зового б ссейн // троительство нефтяных и г зовых скв жин н суше и н море. -2009 . - № 10. - . 34-36.

6. сумов . ., гин . ., врилов . . лушение скв жин с временным блокиров нием продуктивного пл ст н г зовых скв жин х с месторождений р йнего евер // троительство нефтяных и г зовых скв жин н суше и н море. - 2007. - № 9. - .37-40.

7. гин . ., врилов . . зр ботк блокирующего сост в для глушения скв жин н месторождениях п дной ибири с учетом современных требов ний // троительство нефтяных и г зовых скв жин н суше и н море. - 2014. - № 6. - . 38-41.

8 тент № 2543003, $09 \mathrm{~K} 8 / 504$. ост в для временного блокиров ния продуктивного пл ст н водной основе / . . сумов, . . врилов, . . гин , . . остюков // юл. № 6 от $27.02 .2015 ; 3$ явл. 18.03.2014, № 2014110212/03. 
ведения об втор $x$

сумов миз яиевич, Ә. т. н., профессор, 3 служенный деятель н уки, , к демик, первый 3 меститель генер льного директор, «ев в2 з», г. m врополь, тел. 8(8652)563026, e-mail: Priemnaya@scnipigaz.ru

гин исия иховн, к. т. н., ведущий н учный сотрудник, «ев в $е$ з», г. $m$ врополь, mел.8(8652)563026,e-mail: svnipigz@gazprom.ru

остюков ергей л димирович, спир нт, нучный сотрудник, "ев в $е$ з з», г. т врополь, тел.89197405226,e-mail: kostyukovsv@scnipigaz.ru
Information about the authors

Gasumov R. A., Doctor of Engineering, professor, Honored Scientist of RF, academician of RANS, First Deputy CEO, JSC «SevCavNIPIgaz», Stavropol, tel. 8(8652)563026, e-mail:Priemnaya@scnipigaz.ru

Vagina T. Sh., Candidate of Science in Engineering, leading research associate, JSC «SevCavNIPIgaz», Stavropol,tel.8(8652)563026,e-mail: svnipigz@gazprom.ru

Kostukov S. V., postgraduate, researcher, JSC «SevCavNIPIgaz», Stavropol, tel. 89197405226 e-mail: kostyukovsv@scnipigaz.ru 